\title{
Synaptic Actions of Identified Peptidergic Neuron R15 in Aplysia. I. Activation of Respiratory Pumping
}

\author{
A. Alevizos, ' K. R. Weiss, ${ }^{2, a}$ and J. Koester ${ }^{2}$ \\ Center for Neurobiology and Behavior, 'Department of Physiology and Cellular Biophysics and 2Department of Psychiatry, \\ College of Physicians and Surgeons, Columbia University, New York, New York 10032
}

\begin{abstract}
The purpose of the study described in this and the following two companion papers was to determine the synaptic actions of neuron R15, an endogenously bursting neurosecretory cell in Aplysia, as a step toward determining its physiological function. The results described in this paper demonstrate that activity in R15 increases the frequency of bursting in the R25/L25 network that triggers respiratory pumping. This excitatory modulatory effect appears to be mediated by $R 15 \alpha 1$ peptide. R15 activates both strong and weak modes of respiratory pumping. In contrast, the two R20 cells, which are thought to use the neuropeptides $\mathrm{SCP}_{\mathrm{A}}$ and $\mathrm{SCP}_{\mathrm{B}}$ as transmitters, elicit only strong episodes of respiratory pumping. The synaptic actions of $R 15$ also differ from those of the R20 cells in being longer lasting and in exhibiting profound desensitization. Chronic recording of R15 activity in vivo indicates that it does not burst spontaneously in the intact animal, so the synaptic actions of R15 are not chronically densensitized. The neuroendocrine bag cells, which initiate egg laying, had been shown by others to excite R15 and the R25/L25 network that triggers respiratory pumping. Our data indicate that the excitatory effects of the bag cells on the R25/L25 cells are mediated in part by R15.
\end{abstract}

Molluscan neurons that burst spontaneously have proven to be useful experimental preparations for the study of endogenous bursting. Despite all that has been learned about the mechanisms of burst generation and its modulation in these cells, relatively little is known about their physiological functions (Benson and Adams, 1989). Neuron R15, an endogenously bursting cell located in the abdominal ganglion of Aplysia (Strumwasser, 1965), is the most thoroughly studied endogenous burster in any animal (Adams and Benson, 1985). Since the first intracellular recordings from $R 15$ over 30 years ago (Arvanitaki and Chalazonitis, 1958), it has been used as a model system to study a variety of processes, including neuropeptide synthesis and processing (Gainer et al., 1977; Buck et al., 1987; Weiss et al., 1989), synaptic plasticity (Schlapfer et al., 1974), synaptic transmission and electrical excitability (reviewed by Adams and Benson, 1985), and aging (Skinner and Peretz, 1989). Despite

\footnotetext{
Received Apr. 13, 1990; revised Dec. 10, 1990; accepted Dec. 13, 1990.

We thank $M$. Skelton for critically reviewing an earlier draft of this paper. This work was supported by NIH Grants NS14385 and GM32099, National Institute of Mental Health Grant MH36730, a BRSG grant from the NIH, and the Klosk Foundation.

Correspondence should be addressed to Dr. J. Koester, Center for Neurobiology and Behavior, The New York State Psychiatric Institute, 722 West 168 Street, New York, NY 10032.

Present address: Mount Sinai School of Medicine, New York, NY 10029

Copyright (C) 1991 Society for Neuroscience $0270-6474 / 91 / 111263-12 \$ 03.00 / 0$
}

this wealth of cellular and molecular studies, the physiological function of R15 remains unclear. The purpose of the study described in this and the following two companion papers was to determine the synaptic actions of R15, as a step towards understanding its physiological function.

It is thought that R15's synaptic actions are mediated by the release of neuropeptides. R15 was originally hypothesized to be peptidergic on the basis of morphological and biochemical evidence (Coggeshall, 1967; Frazier et al., 1967; Berry, 1976). Recently, Buck et al. (1987) cloned and characterized a cDNA that represents a highly abundant mRNA present in R15. The precursor of this mRNA is spliced differently in different neurons, resulting in two distinct forms of mRNA (R15-1 and R152). The alternative splicing affects only a limited region of the polyproteins encoded by the two forms of mRNA and can produce distinct but overlapping sets of peptides in different neurons. Buck et al. (1987) found that $R 15$ expresses only the R15-2 version of mRNA. The peptides synthesized in R15 and their amino acid sequences were determined by Weiss et al. (1989). Three of the peptides predicted from the sequence of R15-2 mRNA were shown to be synthesized in R15 and were named $\mathrm{R} 15 \alpha 1$ (38 amino acids long), R15 $\beta$ (27 amino acids), and R $15 \gamma$ (37 amino acids). By determining the physiological function of R15, we hope to gain insights into the functional significance of the alternative splicing in this system.

Earlier investigations have produced three lines of evidence suggesting that R15 may be involved in regulation of water balance: (1) Injection of either crude homogenates of $R 15$ or synthetic R15 1 peptide causes water retention (Kupfermann and Weiss, 1976; Weiss et al., 1989). (2) R 15 is inhibited when the semi-intact animal is exposed to hypotonic seawater, and excited when it is exposed to hypertonic seawater (Stinnakre and Tauc, 1969; Woodson and Schlapfer, 1979). (3) Blocking spike activity in R 15 by prolonged hyperpolarization results in alterations of the solute composition of the hemolymph (Bablanian and Treistman, 1985). Although suggestive, these data supporting R15's postulated role in water balance are circumstantial.

Other evidence suggests that R15 may be involved in oviposition. The intensity of $R 15$ bursting is enhanced by a population burst in the neuroendocrine bag cells that elicits egglaying activity (Branton et al., 1978). We investigated the possibility that R15 might mediate various features of egg-laying behavior, such as modulation of respiratory pumping. The frequency of respiratory pumping is thought to increase during egg laying because activation of the bag cells by electrical stimulation in a reduced preparation increases the frequency of spontaneous respiratory pumping (Schaefer and Brownell, 1986). 
Respiratory pumping is a brief, stereotyped behavior, consisting of synchronous gill, siphon, parapodial, and mantle-shelf contractions, accompanied by heart inhibition and decreased vasomotor tone (Byrne and Koester, 1978; Hening, 1982). It occurs spontaneously at variable rates (1-60 events/h) and is thought to serve a respiratory function by promoting ventilation of the gill (Byrne and Koester, 1978).

The neural circuit that controls respiratory pumping includes several dozen identified cells. Many of the motoneurons that mediate respiratory pumping behavior are found in the abdominal and pedal ganglia (Koester and Kandel, 1977; Sawada et al., 1981; Hening, 1982). Two groups of interneurons in the abdominal ganglion that trigger the behavior have been identified and characterized (Byrne, 1983; Koester, 1989). These interneurons, the R25 and L25 cells, constitute two clusters of about 15 cells each. All 30 cells fire in a population burst that drives the motoneurons that generate the stereotyped motor program. The R25 and L25 cells are connected to one another by electrical and chemical synapses. The spontaneous generation of the population burst in the R25/L25 network is mediated by endogenous pacemaker activity of the R25/L25 cells and by reverberation within the network, which results from the electrical and excitatory chemical connections between the members of the network (Byrne, 1983; Koester, 1989). The spontaneous respiratory pumping bursts are usually strong and stereotyped, but respiratory pumping occasionally occurs in a weak mode that is more variable in form (Eberly et al., 1981).

In this paper we demonstrate that R15 excites the R25/L25 network. The actions of R 15 on the R25/L 25 cells are compared and contrasted with those of a pair of peptidergic neurons, the R20 cells, which synthesize the neuropeptides $\mathrm{SCP}_{\mathrm{A}}$ and $\mathrm{SCP}_{\mathrm{B}}$ (small cardiovascular peptides A and B) (Alevizos et al., 1989b). These two neural pathways switch the behavior between its strong and weak modes of operation. In the second paper we demonstrate that $\mathrm{R} 15$ also contracts the pleuroabdominal connectives by exciting the multimodal motoneuron L7 (Alevizos et al., 1991a). In the third paper we show that R15 triggers peristalsis of the large hermaphroditic duct, which transports the egg cordon during egg-laying behavior, and present a hypothesis concerning the role of R15 in integrating various features of egg-laying behavior (Alevizos et al., 1991b).

Some of these results have been described in a preliminary communication (Alevizos et al., 1989a).

\section{Materials and Methods}

Animals. Specimens of Aplysia californica weighing 15-560 gm were supplied by Marinus, Long Beach, CA; Sea Life Supply, Sand City, CA; Alacrity Marine Services, Redondo Beach, CA; and the Howard Hughes Medical Institute Marine Resources Facility at the Woods Hole Oceanographic Institute, Woods Hole, MA. Animals were kept in an aquarium containing artificial seawater (ASW; Instant Ocean) at $14-16^{\circ} \mathrm{C}$ until use.

Intracellular recording. Animals were anesthetized by injection of isotonic $\mathrm{MgCl}_{2}$ (30-40\% of body weight). The isolated abdominal ganglion was dissected from the animal and pinned to the silastic (Sylgard, Dow Corning) bottom of the chamber. In a few experiments, the abdominal ganglion attached to the gill by the genital and branchial nerves was excised, and the gill was attached to an isotonic movement transducer. The recording chamber was filled initially with a modified saline solution containing $192 \mathrm{~mm} \mathrm{Mg} \mathrm{Mg}^{2+}(3.5 \times$ normal $)$ and $5 \mathrm{~mm} \mathrm{Ca}^{2+}$ $(0.5 \times$ normal $)$, prepared by mixing equal volumes of $A S W$ and isotonic $\mathrm{MgCl}_{2}$. ASW was used later in the experiment as the saline solution for bathing the preparation while recording.

The following "non desensitizing washing protocol" was employed in order to prevent the desensitizing effects of the synaptic actions of
R 15 (sce Fig. 9). Bcfore the preparation was washcd with ASW (at lcast 50 bath volumes), R15 was impaled and prevented from firing by hyperpolarizing current injection. After washing, R15 was kept hyperpolarized for at least $2 \mathrm{hr}$ to allow any residual desensitization to decay.

In some experiments, the connective tissue capsule covering the ganglion was dissected before recording to expose the cells of interest for intracellular recording with standard microelectrodes. In other experiments, neurons were impaled by tapping the microelectrode through the sheath of the ganglion. Single-barrel glass microelectrodes (1.2-15 $\mathrm{M} \Omega$ ) filled with $3 \mathrm{M} \mathrm{KCl}$ or $2.5 \mathrm{~m}$ potassium acetate were used to record membrane potential and to inject current into neurons using a bridge circuit. Experiments were performed at room temperature $\left(17-20^{\circ} \mathrm{C}\right)$. Data were tape-recorded and played back on a Gould 2400 chart recorder (full-scale cutoff frequency, $50 \mathrm{~Hz}$ ) for analysis and photographing.

Two methods were used to test for monosynapticity of connections and to minimize polysynaptic effects of applied peptides and neurotransmitters: (1) The threshold for action potential generation was raised by bathing the ganglion in a high-divalent-cation solution containing $165 \mathrm{mM} \mathrm{Mg}^{2+}\left(3 \times\right.$ normal) and $30 \mathrm{mM} \mathrm{Ca}^{2+}(3 \times$ normal). This solution was prepared by mixing isotonic $\mathrm{CaCl}_{2}$, isotonic $\mathrm{MgCl}_{2}$, and $\mathrm{ASW}$. (2) A concentration of $60 \mu \mathrm{M}$ tetrodotoxin (TTX; Calbiochem) was used to block $\mathrm{Na}^{+}$-dependent action potentials. This method does not completely eliminate action potentials, because some $A p l y s i a$ neurons are able to generate $\mathrm{Ca}^{2+}$-dependent action potentials.

In a few experiments, the connections of the abdominal ganglion to the head ganglia by the pleuroabdominal connectives were maintained. The head ganglia were placed in a $1-\mathrm{ml}$ subchamber, to which atrial gland extract (AGE) was introduced in order to excite the bag cells (Painter et al., 1988).

Pharmacology. Peptides and other neurotransmitter substances were applied to the abdominal ganglion as a concentrated bolus added to the bath close to the ganglion from a 50- $\mu$ l pipette. Bath volume was $2 \mathrm{ml}$ in these experiments. Peptide and neurotransmitter solutions were made fresh, from the same batch of ASW used to bathe the preparation. The following peptides were used in this work: $\mathrm{SCP}_{\mathrm{B}}$ (Morris et al., 1982;

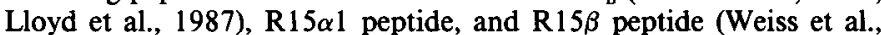
1989). $S_{C C} P_{B}$ and $R 15 \alpha 1$ peptide were purchased from Peninsula Laboratories (Belmont, CA; R15 1 peptide is referred to as "neuron-specific peptide" by Peninsula). R $15 \beta$ peptide was synthesized by the Howard Hughes Medical Institute's Protein Center Core Facility at Columbia University. Atrial gland extract (AGE) was prepared by homogenizing an atrial gland in a glass homogenizer containing $1 \mathrm{ml}$ ASW. The homogenate was centrifuged for $5 \mathrm{~min}$ at $1200 \mathrm{rpm}$, and the supernatant was recentrifuged at the same speed for $10 \mathrm{~min}$. The new supernatant was collected and stored at $-13^{\circ} \mathrm{C}$ until used.

Extracellular recording. Specimens weighing $270-560 \mathrm{gm}$ were used in chronic extracellular recording experiments. The electrode used for chronic recordings, which was made from a flexible silicon polymer (Mirror 3, Kerr Manufacturing Co., Romulus, MI), was based on a design modified from Koch and Brunner (1985). For electrode implantation, the subject was anesthetized with isotonic $\mathrm{MgCl}_{2}(30 \%$ of body weight) and placed in a chamber containing a chilled solution of $1: 1$ ASW/isotonic $\mathrm{MgCl}_{2}$. An incision was made in the body wall to expose the abdominal ganglion and its peripheral nerves. One of the nerves containing an axon branch of $\mathrm{R} 15$ was positioned on the groove of the extracellular electrode (Fig. 1) and was insulated from the hemolymph by means of a latex membrane (Carter-Wallace, New York, NY). The electrode was anchored on the pericardium by 6-0 silk ligature so that its position did not change with movements of the animal. The free end of the wire was passed through the body wall of the animal, to be connected to the extracellular amplifier during the recording sessions. The incision was closed by suturing the body wall and the skin independently. In some experiments, the edges of the skin were glued with Histoacryl (B. Braun, Melsungen, GER). The animal was injected with penicillin $(10,000 \mathrm{U} / \mathrm{ml})$ and streptomycin $(10 \mathrm{mg} / \mathrm{ml} ; 50 \mu \mathrm{l} / \mathrm{ml}$ of body weight) and returned to the aquarium, where it was allowed $24-48 \mathrm{hr}$ to recover before recording. Subjects were housed in a 7.5-liter aquarium of chilled, aerated ASW during the recording sessions, which took place $1.5-4 \mathrm{~d}$ following surgery. At the end of the recording period, which lasted from 1 to $4 \mathrm{~d}$, the animal was killed, and the abdominal ganglion was removed, along with the extracellular electrode connected to the nerve branch. Using this reduced preparation, simultaneous recordings were made from the $\mathrm{R} 15$ cell body and from the chronic nerve electrode, to verify that the R15 burst activity in the nerve branch was clearly recognizable. 
Only the results from animals that were judged to be healthy were tabulated. Criteria for healthiness included relaxation upon handling, normal posture and ability to attach to the substrate, normal feeding bchavior and locomotion, and body weight within $20 \%$ of initial valuc. Of 16 animals in which electrodes were implanted, 9 animals fulfilled all of these criteria. Four additional animals were healthy, but no R15 spike could be identified in the reduced preparation in the branch from which activity was recorded in vivo, due to variability in R15's branching pattern. Chronic recording experiments were done from February through August.

Data presentation and statistical analysis. All data are presented as mean values \pm the standard error of mean (SEM). All statistical analyses of the results were made using a two-tailed $t$ test with a cutoff of $p=$ 0.05 for comparing the difference between means.

\section{Results}

\section{The nondesensitizing washing protocol}

In order to reproducibly demonstrate synaptic actions of R15, we found it necessary to block the spontaneous activity of R15 for a prolonged period. Preliminary experiments indicated that superfusing the abdominal ganglion with the synthetic R15o1 peptide, a putative transmitter of R15, results in a moderate increase in the rate of respiratory pumping. However, a second application of the same concentration of the peptide a few minutes later had no effect on the frequency of discharge of the R25/ L25 network. This decremental effect suggested that the effect of the R15 1 peptide may desensitize, and led us to examine the effects of R 15 and its peptide by means of a special dissection and washing protocol designed to minimize the chronic desensitization of R15's synaptic actions caused by its spontaneous bursting.

The usual dissection procedure with the Aplysia nervous system begins with injection of the animal with a modified saline containing $3.5 \times$-normal $\mathrm{Mg}^{2+}$ and $0.5 \times$-normal $\mathrm{Ca}^{2+}$, which anesthetizes the animal by blocking synaptic transmission. The animal then is dissected, and the abdominal ganglion is removed and pinned to the bottom of the recording chamber in the same saline. Finally, the preparation is washed extensively with ASW and left for $30-60 \mathrm{~min}$ to recover from the dissection before recording is begun. Because R 15 bursts endogenously, it fires during this equilibration period. This spontaneous activity may exert an excitatory modulatory effect on the frequency of bursting of the R25/L25 cells that desensitizes and cannot be observed again in the short term.

Instead of washing the preparation with ASW before the cell penetration, we started our experiments by impaling $R 15$ while the ganglion was still in the high- $\mathrm{Mg}^{2+} / \mathrm{low}-\mathrm{Ca}^{2+}$ solution. The frequency of respiratory pumping was monitored by recording the activity of the $\mathrm{R} 25 / \mathrm{L} 25$ cells directly, or by recording their input to LD and RD cells, which are excited by the R25/L25 cells (Frazier et al., 1967; Koester and Kandel, 1977; the R25/ L25 network was referred to as "interneuron II" in these early reports). R15 was kept hyperpolarized while the preparation was washed extensively with at least 50 bath volumes of ASW. It was not released from hyperpolarization until $2 \mathrm{hr}$ after the impalement, to ensure the decay of any residual desensitization. Using this "nondesensitizing washing protocol," we found that when R 15 was allowed to burst spontaneously or when R15 1 peptide was applied to the ganglion, they had robust effects on the frequency of respiratory pumping. This washing protocol was used for all of the experiments described below.

\section{R 15 bursting increases the frequency of respiratory pumping}

After R15 was released from a 2-hr hyperpolarization and allowed to burst spontaneously for $10 \mathrm{~min}$, there was an increase

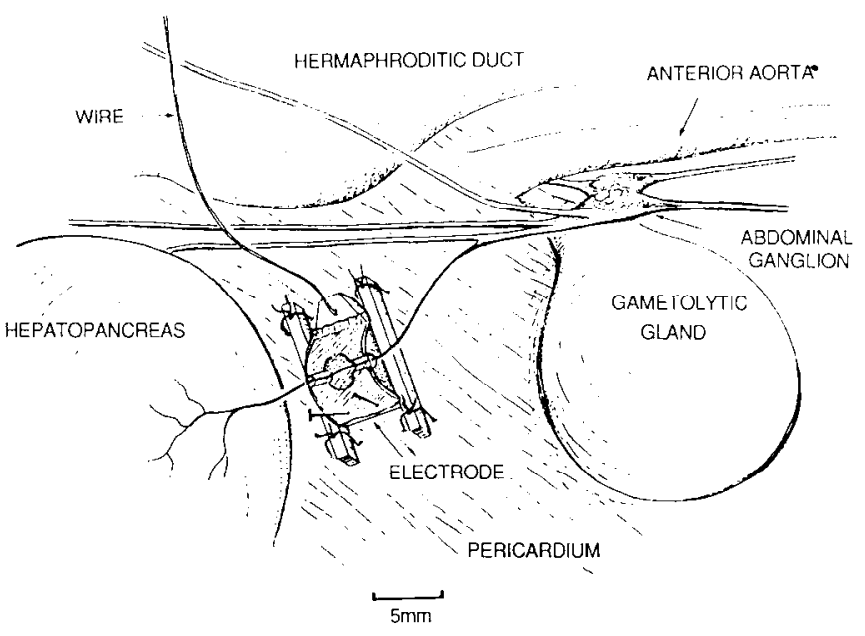

Figure 1. The chronically implanted extracellular electrode. The nerve is positioned in the groove and is isolated from the surrounding medium by means of a thin latex membrane. One side of the membrane is permanently glued to the electrode, and the other is attached, after the nerve is in place, by small pins inserted into the electrode block. One end of an insulated wire is embedded in the polymer, and its bare tip protrudes into a saline-filled chamber through which the nerve runs. The other end of the wire passes through the body wall of the animal and is connected to a preamplifier.

in the frequency of bursting of the R $25 / \mathrm{L} 25$ cells that outlasted the firing of R15. In some experiments, the effect of R15 on the R25/L25 network was observed by monitoring the contractions of the gill, confirming that the bursting activity observed centrally does drive respiratory pumping (data not shown). R15 bursting increased the frequency of respiratory pumping in $94 \%$ of the preparations tested (120 preparations).

When R15 was allowed to burst, it increased the frequency of both weak and strong episodes of respiratory pumping. This is illustrated in Figure $2 A$, in which intense bursts recorded in an $\mathrm{R} 25$ cell are interspersed with weak conjoint excitatory/inhibitory synaptic input. An earlier study showed that subthreshold, conjoint synaptic input such as this is generated when weak episodes of respiratory pumping are driven by the L 25 cells (Koester, 1989). During weak respiratory pumping, only the L25 cells burst, and they fire at a relatively low rate but with a longer burst duration than normal. In contrast, during the strong episodes of pumping, both the R25 and the L25 clusters fire intense, brief bursts of action potentials. The weak bursts in the L25 cluster are transmitted to RD and LD motoneurons that help drive the behavior as low-frequency EPSP bursts, which decay somewhat more slowly than the high-frequency bursts of EPSPs that are generated when both the R25 and the L25 clusters fire synchronously (A. Alevizos, unpublished observations). The difference between the strong and weak bursts recorded in an $\mathrm{L} 25$ cell is illustrated in Figure 2, $C 1$ and $C 2$, which also shows how the 2 burst types can be monitored in a postsynaptic follower of the R25/L25 cells (an LD cell in this case; see Koester, 1989).

The effect of R15 firing on the frequency of respiratory pumping when $\mathrm{R} 15$ is released after a 2-hr hyperpolarization period for $5,10,30$, and $60 \mathrm{~min}$ is shown in Figure 3. The 10-, 30-, and $60-\mathrm{min}$ firing periods of $\mathrm{R} 15$ produce the same maximum effects, which decay with similar time courses. None of the data points of these three curves are statistically different from each 
Figure 2. R15 and the R $15 \alpha 1$ peptide increase the frequency of both weak and strong episodes of respiratory pumping. $A$, Allowing R 15 to fire for $10 \mathrm{~min}$ after a 2-hr hyperpolarization period elicits an increase in the rate of respiratory pumping, as monitored in an $\mathrm{R} 25$ cell. The weak bursts of the R25/L25 network are recorded as a conjoint excitatory/inhibitory synaptic input in this $\mathrm{R} 25$ cell. The strong bursts are marked by stars, and the weak bursts by asterisks. $B$, The R $15 \alpha 1$ peptide mimicked the effect of R15 in the same preparation by increasing the rate of both strong and weak bursts. R 15 was kept hyperpolarized throughout this part of the experiment. The peptide was added as a $50-\mu \mathrm{l}$ bolus of $2 \times 10^{-5} \mathrm{M}, 60 \mathrm{~min}$ after the end of R15 firing. $C$, The intensity of activity in an $\mathrm{L} 25$ cell can be monitored in an LD cell. $C 1$. The brief, high-frequency bursting of the R25/L25 network as monitored in an L25 cell elicits strong bursting in the LD cell. $C 2$, The lower-frequency but longerduration bursting in an L25 cell contributes to a weaker, longer-lasting synaptic input in the LD cell. The LD cell was kept hyperpolarized to reduce background activity, so that the synaptic inputs from the R25/L25 network could be distinguished easily.

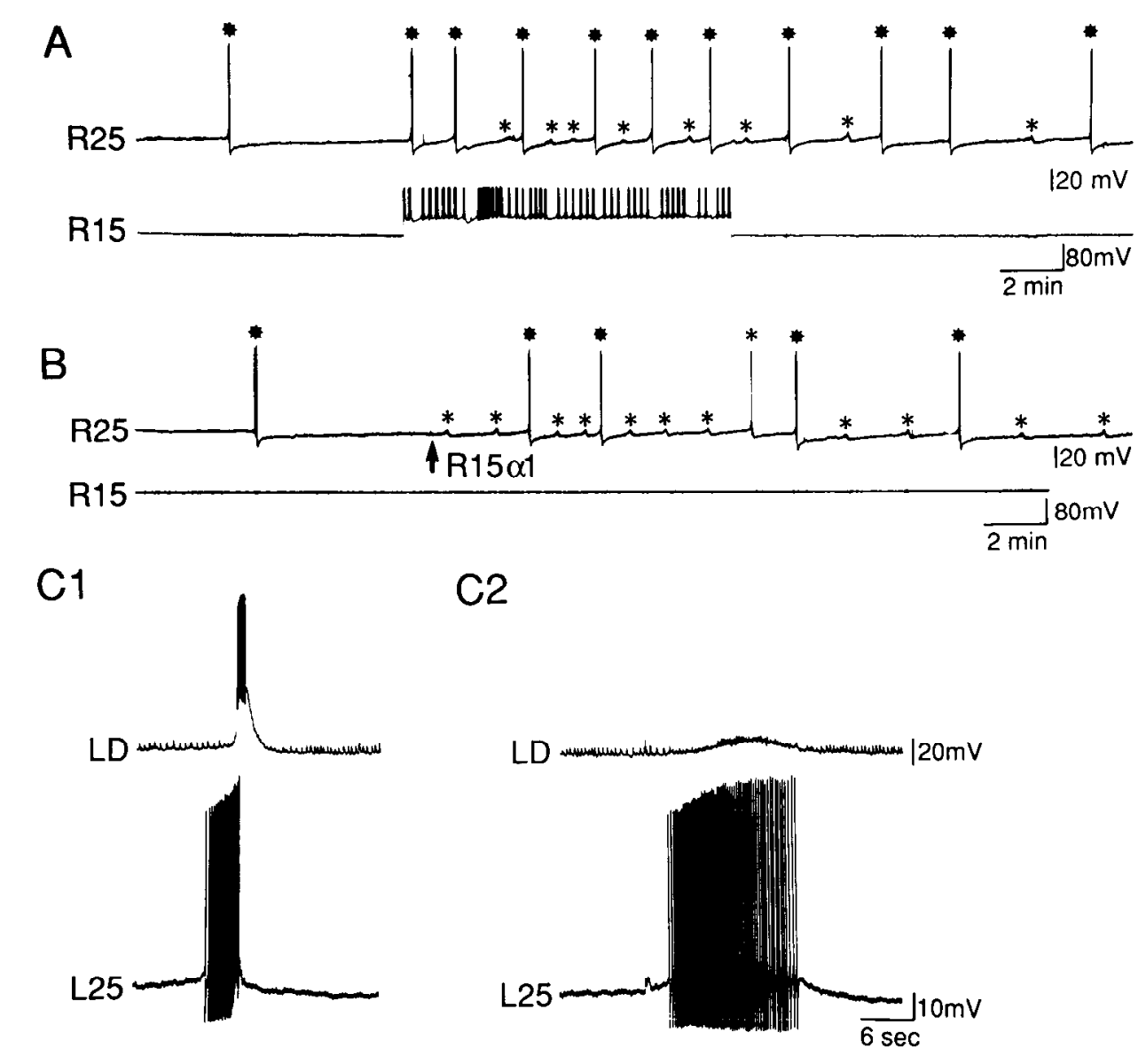

other at any time point after R 15 has begun to fire, while they all differ from the responses produced by the 5 -min release of $\mathrm{R} 15$. These results show that R15's effect reaches its maximum within 5-10 min after the start of spontaneous bursting and then decays over several minutes.

This effect of R15 on the rate of respiratory pumping has been overlooked previously, presumably because the effect decays with repeated $\mathrm{R} 15$ firing and it requires a long period of hyperpolarizing R15 to renew the responsiveness of the system. The response to firing $R 15$ partially recovered when the interval between bursts was increased from 40 to $80 \mathrm{~min}$ (Fig. 4). These experiments began with a 2-hr hyperpolarization of R15, so they ran for several hours. As a result, the basal bursting frequency of respiratory pumping and the responsiveness of the R25/L25 cells decreased with time, which may account for the fact that recovery was not complete. In two additional experiments, R15 was not prevented from firing during the washing period, and it was hyperpolarized for periods of only $10 \mathrm{~min}$, every 30 min (three R 15 bursting periods of 30 min each separated by two hyperpolarization periods of $10 \mathrm{~min}$ each). No effect of R 15 firing on the frequency of respiratory pumping was observed in these experiments (data not shown), consistent with the conclusion that the effect of $\mathrm{R} 15$ on the $\mathrm{R} 25 / \mathrm{L} 25$ cells wanes upon continuous and prolonged spontaneous firing of R15.

$R 15 \alpha 1$ peptide may mediate the excitation of the $R 25 / L 25$ network by $R 15$

To test the possibility that $\mathrm{R} 15 \alpha 1$ peptide may mediate the effect of R 15 on the R25/L25 network, the peptide was applied to the solution bathing the ganglion. $\mathrm{R} 15 \alpha 1$ peptide increased the rate of respiratory pumping in a dose-dependent manner (Fig. 5), and it had the same qualitative effect as R15: it elicited both strong and weak bursts (see Figs. $2 A, B ; 10 ; 11$ ). Thus, R15 1 pcptide is a good candidate for mediating the excitatory effects of R15 on the R25/L25 network.

In order to determine whether the effects of R15 and of the $\mathrm{R} 15 \alpha 1$ peptide on the R25/L25 network are direct, two experiments were performed in which polysynaptic transmission in the ganglion was reduced. In the first set of experiments, TTX was used to block $\mathrm{Na}^{+}$-dependent action potentials in the ganglion, thereby blocking most synaptic transmission. TTX completely blocks the action potentials in the R25/L25 cells, revealing the endogenously generated plateau potentials that underlie the bursting of these cells (Koester, 1989). Although the $\mathrm{Na}^{+}$component of the action potentials in $\mathrm{R} 15$ is also blocked by TTX, R15 still can generate $\mathrm{Ca}^{2+}$-dependent action potentials. Firing R 15 at $5 \mathrm{~Hz}$ while the preparation is bathed in TTX increases the frequency, duration, and amplitude of the plateau potentials monitored in an R25 cell (Fig. 6A). Similarly, bath application of the R $15 \alpha 1$ peptide in the presence of TTX increases the frequency, duration, and amplitude of the plateau potentials recorded in R 25 cells (Fig. $6 \mathrm{~B}$ ). In the second set of experiments, a solution of high divalent cations was used to block polysynaptic pathways. Allowing R15 to burst while the ganglion is bathed in this solution produces a long-lasting depolarization of an $\mathrm{R} 25$ cell (Fig. $6 \mathrm{C}$ ). In a similar fashion, application of the $R 15 \alpha 1$ peptide while the ganglion is bathed in the same high-divalent-cation solution produces a long-lasting 


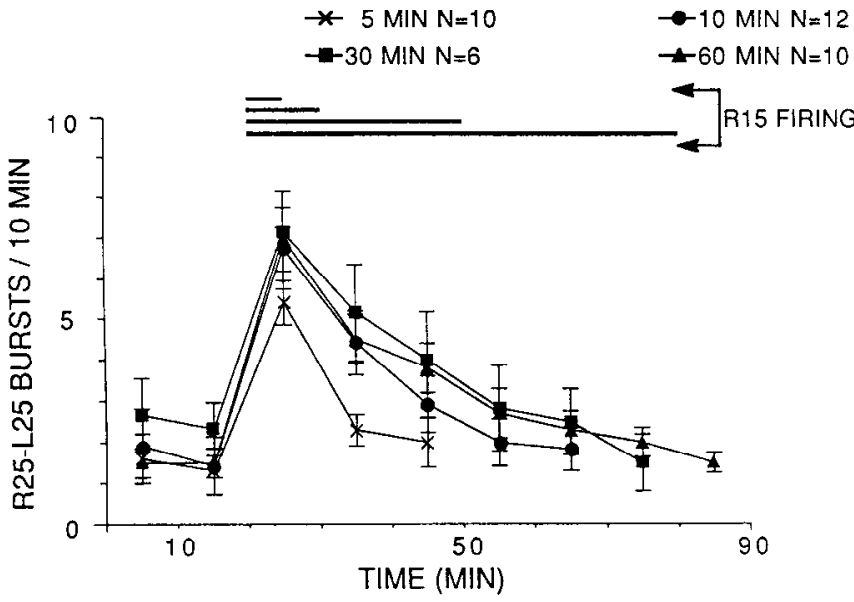

Figure 3. Modulation of the frequency of respiratory pumping by R15 decays during prolonged $R 15$ activity. When $R 15$ was allowed to burst spontaneously for various amounts of time after a 2-hr hyperpolarization period, it produced a long-lasting increase in the frequency of respiratory pumping. The amplitudes of the maximum effect and the time courses of decay of these increases were not significantly different for the 10-, 30-, and 60-min firing periods, while the effect produced by the 5-min firing was significantly smaller in both amplitude and duration. These data indicate that the maximum effect of R15 bursting is exerted within the first 5-10 min of bursting, beyond which the response is independent of R15 activity. Respiratory pumping frequency was monitored via R25/L25 network followers. There was no significant difference in mean firing rate of R15 in the four groups, nor was there a trend for the firing rate of R15 to slow down over the course of the long burst periods (data not shown). The mean of the group firing rates of R15 under the four burst conditions was $0.7 \mathrm{~Hz}$. Error bars represent SEM.

depolarization of the R25 cell (Fig. 6D). The effects of both R15 and the $\mathrm{R} 15 \alpha 1$ peptide applied in high-divalent-cation solution are shorter lasting than when they are applied in ASW. This reduced time course of the effect may be due either to some direct effect of the divalent cations on the receptor, channel, or second messenger that mediates the effect, or to a polysynaptic component of the pathway that is blocked under high-divalentcation conditions.

In order to test whether the excitatory effect of R15 on the $\mathrm{R} 25 / \mathrm{L} 25$ network desensitizes, R15 was released from hyperpolarization for $10-\mathrm{min}$ periods at brief time intervals. The responses of the R25/L25 network to this protocol then were compared to those for a similar protocol of application of exogenous R15 $\alpha 1$ peptide. The response to the second period of $\mathrm{R} 15$ bursting is smaller than that to the first period (Fig. $7 A$ ). This decrement in response, which is statistically significant, could be due to presynaptic depression. However, a similar effect is produced by successive applications of a constant dose of R $15 \alpha 1$ peptide. The second application of the peptide produces a significantly smaller effect than the first (Fig. 7B). Assuming that $R 15 \alpha 1$ peptide is the transmitter used by $R 15$, these results suggest that the decay in responsiveness to $\mathrm{R} 15$ activity is more likely to result from desensitization, refractoriness, or slowly developing synaptic inhibition of the R25/L25 network than from presynaptic depression.

To examine whether these decrements in responsiveness to R15 activity can be attributed to refractoriness or inhibition of the R25/L25 cells, the R25/L25 network was excited by application of $\mathrm{SCP}_{\mathrm{B}}$ following the second firing period of $\mathrm{R} 15$ (Fig. $7 A$ ). $\mathrm{SCP}_{\mathrm{B}}$ is not present in $\mathrm{R} 15$ (Lloyd et al., 1985), but it is

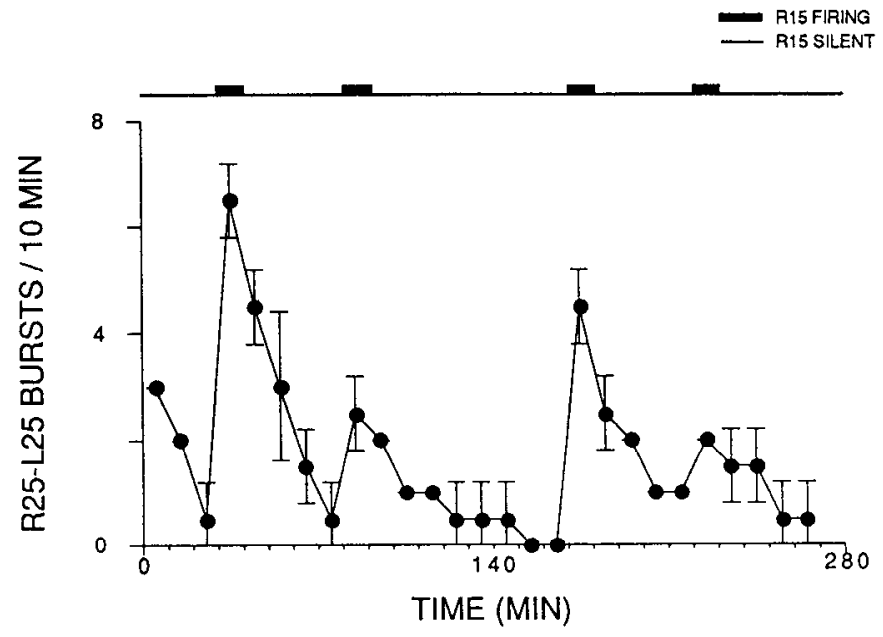

Figure 4. Recovery of the effect of R15 on respiratory pumping rate requires a prolonged hyperpolarization of R15. Allowing R15 to burst spontaneously for $10 \mathrm{~min}$ after a 2 -hr hyperpolarization period produces a long-lasting increase in the rate of respiratory pumping $(N=2)$. After $40 \mathrm{~min}, \mathrm{R} 15$ was released again from hyperpolarization for $10 \mathrm{~min}$. The effect of R 15 bursting was significantly smaller during the second firing period. Allowing an 80 -min recovery period in $\mathrm{R} 15$ partially restored the initial effect on the respiratory pumping frequency. $R 15$ was released from hyperpolarization for a fourth $10-\mathrm{min}$ period, $40 \mathrm{~min}$ from the end of the third firing period. The effect of R15 on the respiratory pumping rate was again attenuated relative to the third firing period. The number of spikes in R15 did not change appreciably from the first bursting period to the last $(328,335.5,355$, and 337.5 spikes for each successive 10-min firing period), so the changes in the rate of respiratory pumping cannot be attributed to the small differences observed in the number of spikes in R15. Error hars represent SEM.

synthesized by the two R20 cells and is likely to be used as a transmitter by the R20 cells for exciting the R25/L25 network (Alevizos et al., 1989b). The frequency of respiratory pumping increased when $\mathrm{SCP}_{\mathrm{B}}$ was applied in this protocol. This increase

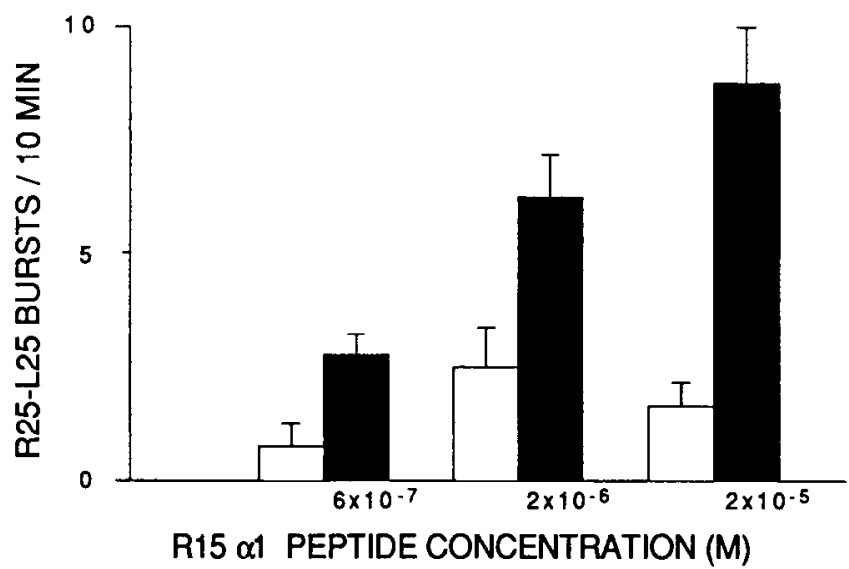

Figure 5. The R15 $\alpha 1$ peptide mimicks the effect of R 15 on the frequency of respiratory pumping. Open bars show the rates of respiratory pumping before adding the peptide. The $\mathrm{R} 15 \alpha 1$ peptide was added near the ganglion from a pipette, as a $50-\mu \mathrm{l}$ bolus, at the concentrations indicated under the solid bars. The preparation was continuously superfused with ASW at a rate of $1-1.5 \mathrm{ml} / \mathrm{min}$. The effect of the peptide is expressed in a dose-dependent manner, with higher concentrations producing stronger effects. The strong episodes of respiratory pumping were monitored in R25/L25 nctwork followers $\left(N=4\right.$ for $6 \times 10^{-7} \mathrm{M}$ and $2 \times 10^{-6} \mathrm{M} ; N=8$ for $\left.2 \times 10^{-5} \mathrm{M}\right)$. R15 was kept hyperpolarized throughout these experiments. Error bars represent SEM. 
Figure 6. $\mathrm{R} 15$ and the R15 1 peptide act directly on the R25/L25 cells. $A$, Bathing the ganglion in TTX $(60 \mu \mathrm{M})$ reveals endogenously generated plateau potentials that underlie the bursts in the R25/L25 network (Koester, 1989) and reduces polysynaptic activity by eliminating $\mathrm{Na}^{+}$-dependent spikes. Firing $\mathrm{R} 15$ at $5 \mathrm{~Hz}$ prolongs the duration and increases the amplitudes and the frequency of the plateau potentials in the R25/L25 network $(N=5) . B$, Applying R $15 \alpha 1$ peptide mimicks the effects of R15 on the plateau potentials of the R25/L25 cells $(N=5)$. $C$, Releasing $\mathrm{R} 15$ from hyperpolarization elicits a long-lasting depolarization in an R25 cell, even with the ganglion bathed in a solution of high divalent cations to reduce polysynaptic transmission $(N=3)$. $D$, Adding $\mathrm{R} 15 \alpha 1$ peptide while the ganglion is superfused with high-divalent-cation solution produces a long-lasting depolarization of an $\mathrm{R} 25$ cell $(N=3)$. A $50-\mu$ l bolus of 2 $\times 10^{-5}$ M R $15 \alpha 1$ peptide (arrows) was added near the ganglion in $B$ and $D$.
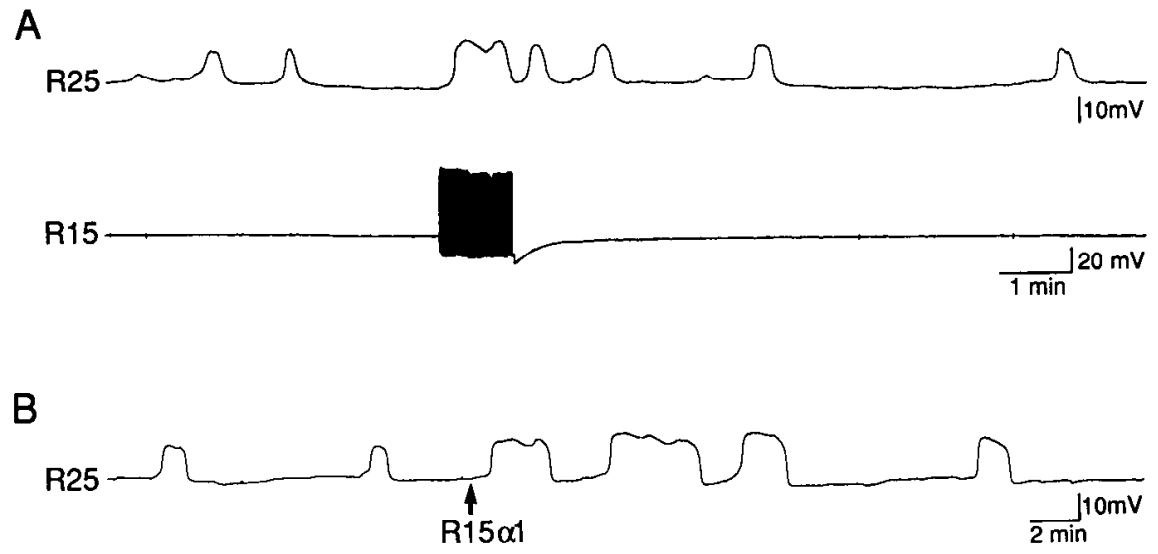

C

D

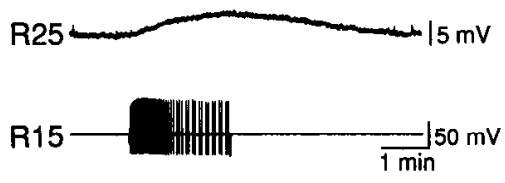

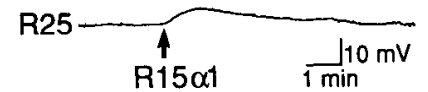

was within the usual range of the $\mathrm{SCP}_{\mathrm{B}}$ effect and not significantly different from the response when SCP application was not preceded by R15 firing ( $N=5$; data not shown).

Further evidence that the decreased responsiveness to successive R 15 firings is not due to refractoriness of the R25/L25 cells comes from an experiment in which the synaptic actions of R 15 and an R 20 cell were interacted. Firing an R20 cell at $3 \mathrm{~Hz}$ for $10 \mathrm{~min}$ elicited a large increase in R25/L25 activity. Nevertheless, when R15 was released from hyperpolarization for $10 \mathrm{~min}$, it produced an increase in respiratory pumping rate that was not statistically different from that which occurs when the R15 bursts are not preceded by R20 activity (Fig. 8).

The lack of specific antagonists for the $R 15 \alpha 1$ peptide receptor makes it difficult to test conclusively whether this peptide mediates the postsynaptic actions of R15. However, the fact that the effects of R15 and its peptide decrement with repetition suggested that application of a high concentration of the peptide and prolonged firing of R15 might cross-desensitize. Successive applications of the peptide do indeed desensitize the response of the R25/L25 cells. Allowing R15 to burst after the response to the peptide has been desensitized does not produce a significant increase in the respiratory pumping rate (Fig. 9A). Application of $\mathrm{SCP}_{\mathrm{B}}$ at the end of the experiment shows that the R25/ L25 cells are neither refractory nor does R15 1 peptide cause them to be inhibited via another pathway, because they still can be modulated normally by $\mathrm{SCP}_{\mathrm{B}}$. Similarly, allowing $\mathrm{R} 15$ to burst for 60 min desensitizes the R25/L25 cells, blocking the response to a second firing of $\mathrm{R} 15$ and to the application of the R $15 \alpha 1$ peptide (Fig. 9B). This concentration of R $15 \alpha 1$ peptide normally would be expected to produce a 2.5 -fold increase in the rate of respiratory pumping (Fig. 5). The two cross-desensitization experiments illustrated in Figure 9 suggest that R15 and the R15 1 l peptide use the same receptor or the same postreceptor signal-transduction mechanism to generate their effects, so it is likely that the R $15 \alpha 1$ peptide mediates R 15 's synaptic actions on the R $25 / \mathrm{L} 25$ cells. Moreover, these results support the hypothesis that the decay in the responsiveness of the R25/L25 network to repeated firing of R15 results largely from desensitization, though an additional effect due to decreased transmitter release cannot be ruled out.

We also tested one of the other two neuropeptides known to be present in $\mathrm{R} 15$, the R $15 \beta$ peptide, for its actions on the R25/ $\mathrm{L} 25$ network. Bath application of this peptide produced no effect on the frequency of respiratory pumping, nor did R $15 \beta$ peptide modulate the response of the R25/L25 network to the R $15 \alpha 1$ peptide or to the firing of R15 (Alevizos, 1989). These experiments suggest that the $R 15 \beta$ peptide acts neither presynaptically, to inhibit or promote release from $\mathrm{R} 15$, nor postsynaptically, to modulate the response of the R25/L25 cells to R15. Of course, other peptides synthesized or processed (posttranslationally modified) in $\mathrm{R} 15$ may play a presynaptic or postsynaptic role in synaptic transmission by $\mathrm{R} 15$. The $\mathrm{R} 15 \gamma$ peptide was not tested because it is not available in synthetic form.

\section{Comparison between the effects of $R 15$ and the R20 cells on respiratory pumping}

As an additional test of the hypothesis that $\mathrm{R} 15 \alpha \mathrm{l}$ peptide mediates the synaptic actions of R15 on the R25/L25 network, the synaptic actions of $R 15$ were compared to the actions produced by direct application of the peptide and to the effects produced by the only other known excitatory modulator of the network, the $\mathrm{R} 20$ cells, and one of their putative transmitters, $\mathrm{SCP}_{\mathrm{B}}$. As described above, the R25/L25 network exhibits two distinct modes of activity: weak bursts (L25 cells bursting alone) and strong bursts (R25 and L 25 cells bursting together). R 15 bursting was found to increase the frequency of both weak and strong bursts in the R25/L25 network, with about the same time courses (Figs. 2A, 10A). A similar effect was produced by application of $\mathrm{R} 15 \alpha 1$ peptide onto the abdominal ganglion (Figs. $2 B, 10 B$ ). Weak bursting was observed in $78 \%$ of the preparations in which R15's synaptic actions were recorded $(N=120)$ and $80 \%$ of the preparations in which the effects of R15 1 peptide were recorded $(N=75)$. In those preparations in which only strong bursting was observed, we cannot exclude the possibility that 
A

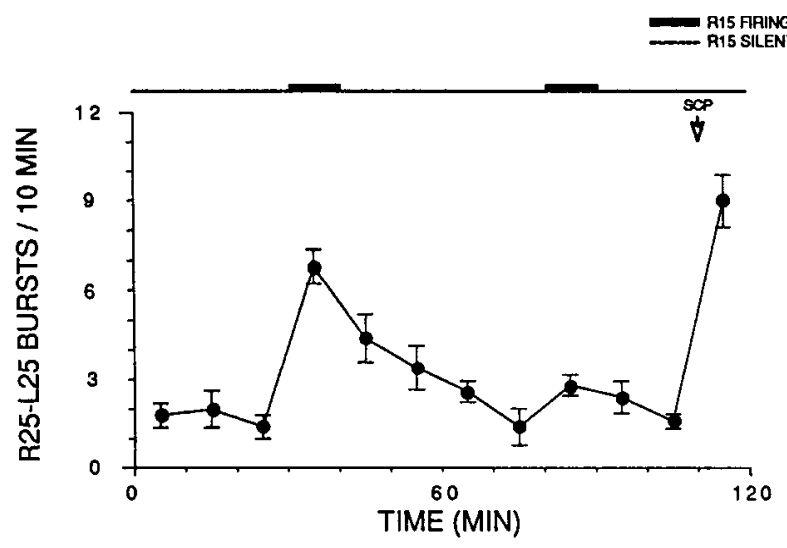

B

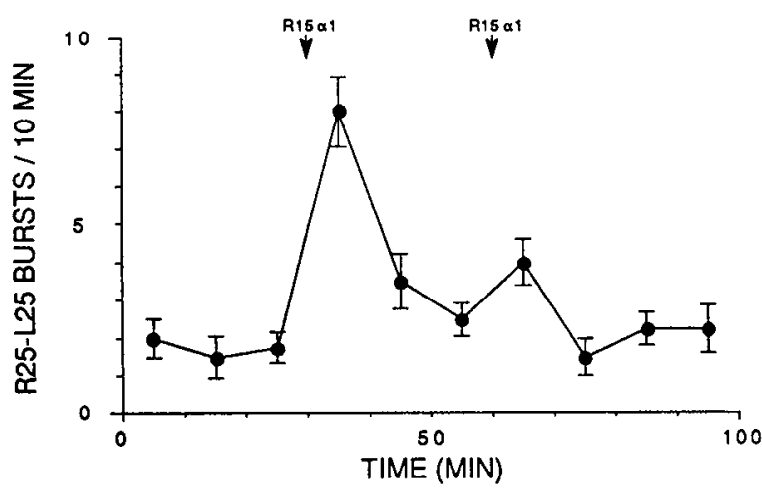

Figure 7. The effects of R15 and the R15a1 peptide on the frequency of respiratory pumping decay with repetition. A, Allowing $\mathrm{R} 15$ to burst spontaneously for $10 \mathrm{~min}$ after a 2-hr hyperpolarization elicits a longlasting increase in the frequency of respiratory pumping. Releasing R 15 from hyperpolarization $40 \mathrm{~min}$ after the end of the first firing period produces an effect on the respiratory pumping rate that is significantly smaller than that produced during the first firing period $(N=4)$. The number of spikes in R15 increased during the second firing period by $2.8 \%$. Application of $\mathrm{SCP}_{\mathrm{B}}$ produced a large increase in the rate of respiratory pumping (not significantly different from the effect of applying $\mathrm{SCP}_{\mathrm{B}}$ without prior $\mathrm{R} 15$ activity; $N=4$ ), suggesting that the $\mathrm{R} 25$ / L25 cells are not refractory or inhibited by another pathway. $B$, Application of $\mathrm{R} 15 \alpha 1$ peptide elicits a fourfold increase in the respiratory pumping rate. A bolus of R15 peptide added $40 \mathrm{~min}$ after the first bolus produces a significantly smaller effect $(N=4)$. All $\mathrm{SCP}_{\mathrm{B}}$ and R15 151 applications in $A$ and $B$ consisted of a $50-\mu$ l bolus of $2 \times 10^{-5} \mathrm{M}$ delivered near the ganglion. Error bars represent SEM.

weak bursting occurred but could not be recorded in the follower cells selected to monitor R25/L25 network activity.

Firing R 15 or applying R $15 \alpha 1$ peptide produces effects on the $\mathrm{R} 25 / \mathrm{L} 25$ network different from those produced by the R20 cells or by $\mathrm{SCP}_{\mathrm{B}}$. The R20 cells and $\mathrm{SCP}_{\mathrm{B}}$ exclusively generate strong bursting with a decelerating pattern, while R 15 and the $\mathrm{R} 15 \alpha 1$ peptide produce both weak and strong R25/L25 bursts that are more evenly spaced in time. The weak bursts, as monitored by the synaptic potentials in RD or LD followers, are not stereotyped in amplitude and form, while the strong bursts are more homogeneous (Fig. 11).

Another indication that R15 and the R20 cells have qualitatively different effects on the R25/L25 network comes from comparing the time courses of their synaptic actions. If $R 15$ is

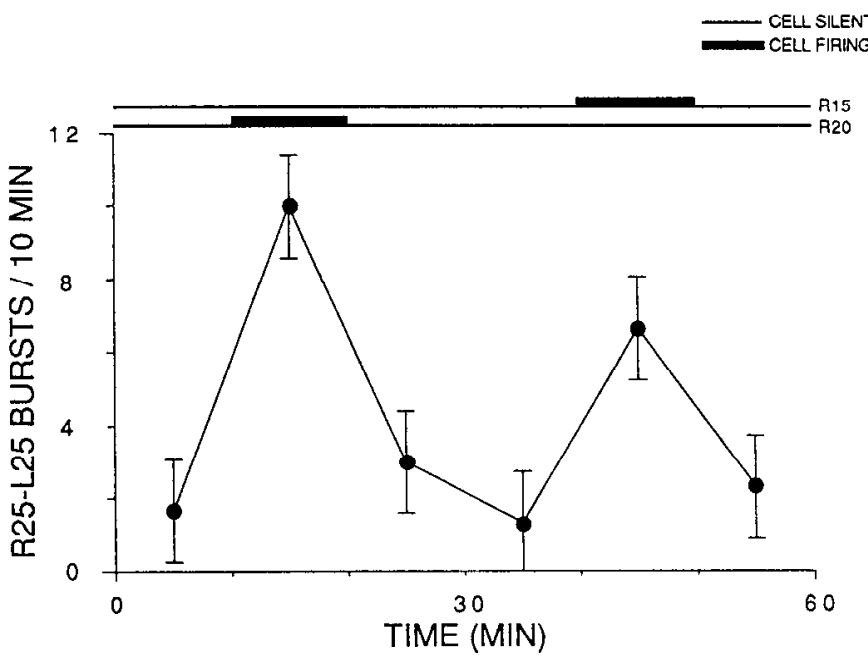

Figure 8. Previous activity elicited in the R25/L25 network by another input does not reduce the responsiveness of the network to R 15 . Firing an $\mathrm{R} 20$ cell at $3 \mathrm{~Hz}$ for 10 min elicits a fivefold increase in the frequency of respiratory pumping. $R 15$ was kept hyperpolarized from the start of the experiment and was released from hyperpolarization $20 \mathrm{~min}$ after the end of firing in the R20 cell. R15 bursting produced a 3.5-fold increase in the frequency of respiratory pumping, which was not significantly different from the effect produced by $\mathrm{R} 15$ bursting that was not preceded by R20 firing (data not shown; $N=3$ ). Error bars represent SEM.

fired at $3 \mathrm{~Hz}$ for $10 \mathrm{~min}$, it produces an increase in the rate of bursting of the R25/L25 cells that decays over $60 \mathrm{~min}$, while firing an R20 cell at the same frequency for the same period of time produces an effect that decays over $20 \mathrm{~min}$ (Fig. 12). This result is consistent with the conclusion that the two cell types use different transmitters.

\section{Physiological function of activation of the R25/L25 network by RI5}

The fact that R15 is excited by the bag cells (Branton et al., 1978) suggests that it might mediate excitatory actions of the bag cells on the R25/L25 network. To test this hypothcsis, wc initiated a population burst in the bag cells by bathing the head ganglia with AGE, as described by Painter et al. (1988). In these experiments, R15 was kept hyperpolarized for a period beginning $2 \mathrm{hr}$ before the application of AGE. The bag cell burst triggered indirectly by AGE had no effect on the frequency of R25/L25 burst activity until R15 was released from hyperpolarization, $15 \mathrm{~min}$ after the beginning of the bag-cell burst. As soon as R15 was allowed to burst, the frequency of R25/L25 bursting began to increase (Fig. 13; see also Alevizos et al., 1991b). In a separate set of experiments, when R15 was kept hyperpolarized throughout the experiment, the bag-cell burst had no significant effect on the frequency of respiratory pumping $(N=3)$.

\section{$R 15$ does not burst spontaneously in the intact animal}

Because R 15 is excited by the neurocndocrine bag cells when they trigger egg laying, we suggest that $\mathrm{R} 15$ 's motor effects described here and in the two companion papers (Alevizos et al., 1991a,b) may be involved in egg-laying behavior. Two observations, considered together, argue against this hypothesis. First, the synaptic actions of R15 decrement rapidly with prolonged firing of R15, apparently due to desensitization. Second, R15 
A

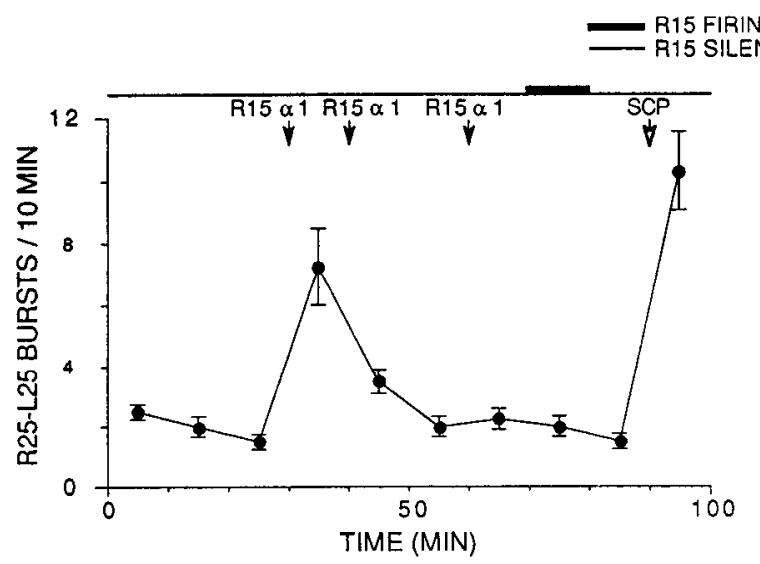

$\mathbf{B}$

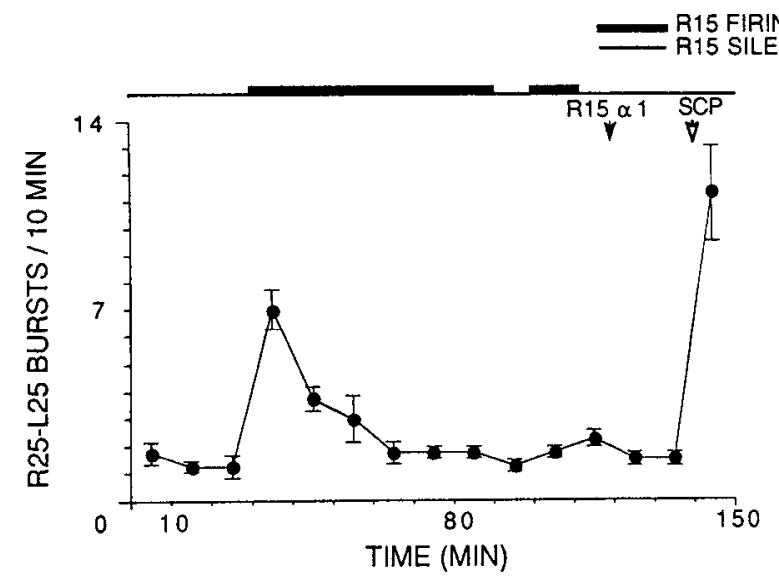

Figure 9. R15 and R15 $\alpha 1$ peptide act on the R25/L25 network through the same receptor or postreceptor mechanism. $A$, Two successive applications of the R15 $\alpha 1$ peptide render the R25/L25 network insensitive to a third application of peptide. Releasing R 15 from hyperpolarization after the third application results in no effect on the frequency of respiratory pumping $(N=4)$. $\mathrm{SCP}_{\mathrm{B}}$ applied $10 \mathrm{~min}$ after the $\mathrm{R} 15$ firing increases significantly the rate of respiratory pumping. R15 was kept hyperpolarized throughout the experiment. The preparations were not perfused during these experiments, and the peptides were presented as $50-\mu \mathrm{l}$ boluses of $2 \times 10^{-5} \mathrm{M}$ applied near the ganglion. $B$, Allowing R15 to fire spontaneously for $60 \mathrm{~min}$ after a $2 \mathrm{hr}$ hyperpolarization period results in an increase in the frequency of respiratory pumping, which decays over a $60-\mathrm{min}$ period. The $\mathrm{R} 25 / \mathrm{L} 25$ network becomes insensitive to a second 10-min period of firing R15, and application of the R15 1 peptide as a $50-\mu 1$ bolus of $2 \times 10^{-6} \mathrm{M}$, a concentration that normally elicits a 2.5 -fold increase in the rate of respiratory pumping, has no effect. $\operatorname{SCP}_{\mathrm{B}}\left(50 \mu \mathrm{l}\right.$ of $\left.2 \times 10^{-5} \mathrm{M}\right)$ applied $10 \mathrm{~min}$ later produces a significant increase in the rate of respiratory pumping $(N=4)$. Error bars represent SEM.

bursts continuously in the isolated ganglion and in the isolated nervous system (Beiswanger and Jacklet, 1975; Lickey et al., 1976). Thus, R15's synaptic actions are chronically in a refractory state in vitro, and they can be demonstrated only if R15 is hyperpolarized for $1-2 \mathrm{hr}$ to prevent it from firing. Given this combination of continuous bursting activity and robust desensitization, can the synaptic actions of R15 ever be expressed physiologically? Perhaps R 15 bursting is less active in the intact, freely behaving animal than in the various reduced preparations from which it has been recorded. We recorded the activity of $\mathrm{R} 15$ in the intact animal in order to test this hypothesis.

In earlier studies, Pinsker and colleagues attempted to monitor R15 activity in intact animals by recording extracellularly from the axons of R 15 in peripheral nerves or from its cell body
A

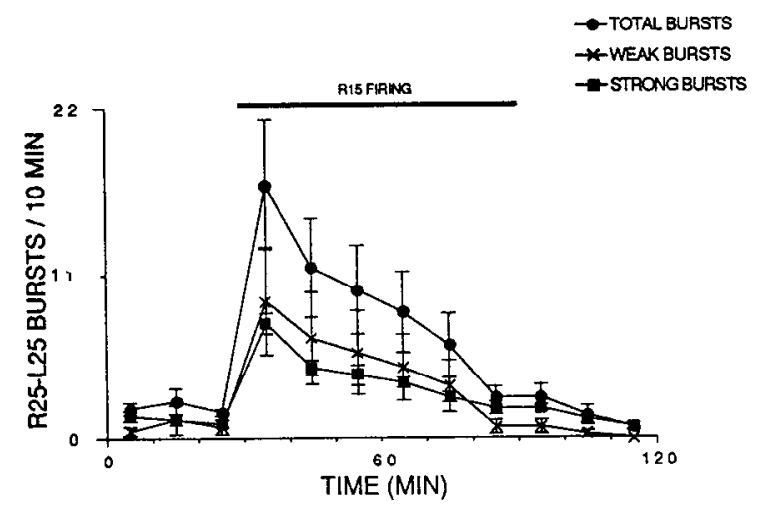

$\mathbf{B}$

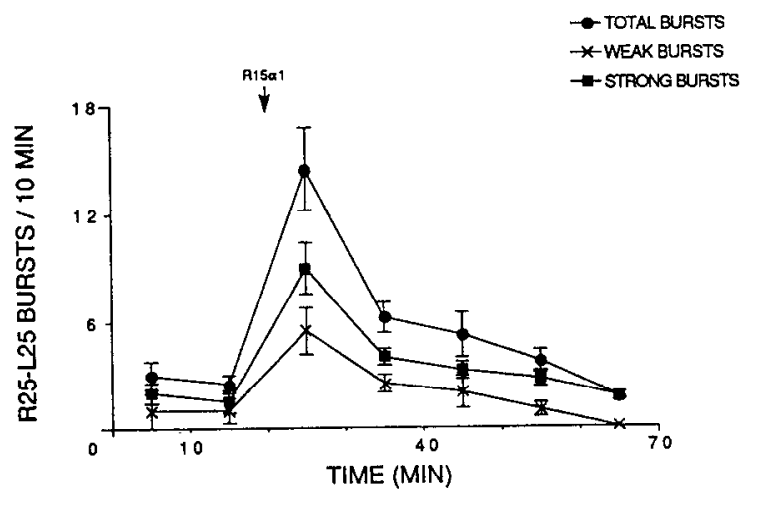

Figure 10. R15 and the R15 $\alpha 1$ peptide produce both strong and weak bursting of the K25/L25 network. $A$, Firing R 15 by brief current pulses at $1.8 \mathrm{~Hz}$ for $60 \mathrm{~min}$ after a 2 -hr hyperpolarization elicits an increase in the frequency of respiratory pumping, which consists of both strong and weak bursting. The weak and strong bursting decay with similar time courses. The graph shows the amplitudes and durations of the increases in frequency of weak, strong, and total number of bursts of the R25/L25 network in response to R 15 firing $(N=4)$. $B$, Application of $\mathrm{R} 15 \alpha 1$ peptide mimicks the effect of $\mathrm{R} 15$ on the frequency of respiratory pumping, in that it generates both weak and strong bursts in the R25/L25 network. The graph shows the amplitudes and durations of the increases in frequency of weak, strong, and total number of bursts of the R25/L25 network in response to $\mathrm{R} 15 \alpha 1$ peptide, which was given as a $50-\mu \mathrm{l}$ bolus of $2 \times 10^{-5} \mathrm{M}$, presented close to the ganglion $(N=4)$. Error bars represent SEM.

(ter Maat et al., 1983; Parsons et al., 1983). They could not definitively identify R15 spike activity in the genital and pericardial nerves (Ter Maat et al., 1983), and attempts to record chronically from the soma of R 15 also yielded ambiguous results (D. W. Parsons, personal communication). In acute experiments performed by Bablanian and Treistman $(1983,1985)$, intracellular recordings were made from R 15 while the abdominal ganglion was exposed through a slit on the body wall in animals that were restrained by pinning the foot and the parapodia. R 15 burst occasionally in these experiments, but fired primarily in a synaptically driven mode. However, potentially noxious afferent stimuli resulting from opening and pinning out the animal are likely to have influenced the firing of the cell.

We chose to record axonal activity of R15 in the intact animal. The main branches of the pericardial, genital, and siphon nerves have high background activity, making it difficult to identify the R15 spike in these branches. Therefore, we attempted to improve the signal-to-noise ratio by recording from nerves that had relatively few axons other than that of $R 15$. The best nerves in this regard are the fine branches of the pericardial nerve that innervate the sheath of the hepatopancreas. As demonstrated 

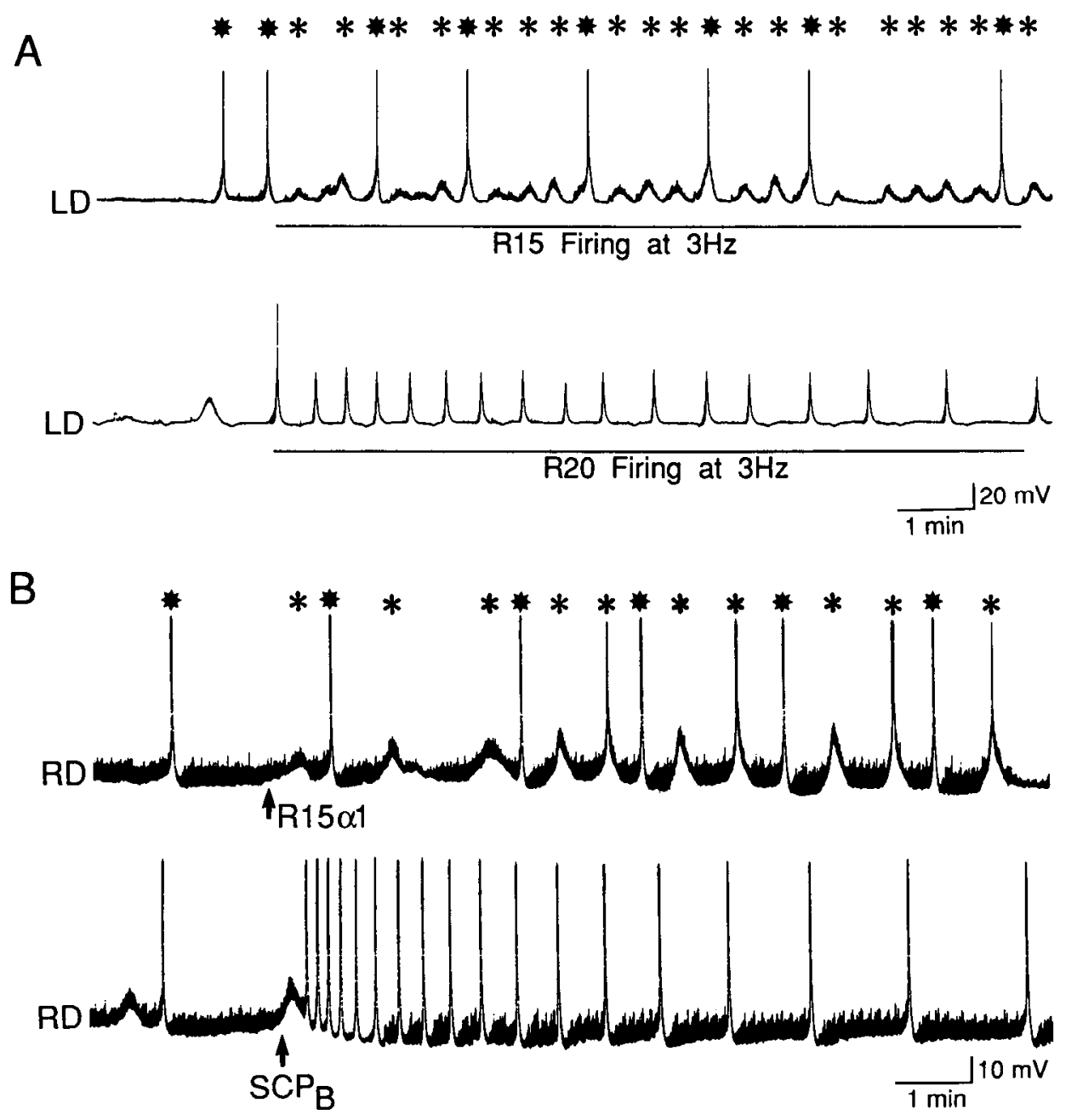

Figure 11. The R25/L25 network responds differently to R15 and the R 20 cells and to their putative transmitters. $A$, Firing R 15 for $10 \mathrm{~min}$ at $3 \mathrm{~Hz}$ after a 2-hr hyperpolarization generates weak and strong bursting of the R25/L25 cells, monitored in an LD cell. Strong bursts are marked by stars and weak bursts are marked by asterisks. Note that the weak bursts are not stereotyped in amplitude and shape. In the same preparation, firing an $\mathrm{R} 20$ cell for $10 \mathrm{~min}$ at $3 \mathrm{~Hz}$ produces only strong bursting, which produces synaptic input that is stereotyped in shape and amplitude. The strong bursts elicited by firing $\mathrm{R} 20$ are less effective in triggering spikes in the LD cell because R20 weakly inhibits this $\mathrm{LD}$ cell. $B$, The $\mathrm{R} 15 \alpha 1$ peptide mimicks the effect of R15 on the frequency of respiratory pumping by eliciting both strong (stars) and weak bursts (asterisks), as monitored in an RD cell. $\mathrm{SCP}_{\mathrm{B}}$ generates only strong bursts, as monitored in the same RD cell. Both peptides were applied in $50-\mu \mathrm{l}$ boluses of $2 \times 10^{-5} \mathrm{M}$. The records in $A$ and $B$ are from different preparations. In both $A$ and $B$, the LD and the RD follower cells were hyperpolarized to reduce spike activity, thereby making the synaptic input from the R25/L25 network more apparent. by Rittenhouse and Price (1985), there is very little electrical activity in vitro in these branches, other than that attributed to R15. Although there is some variability in which branches contain R15 axons, the low background activity in these nerves makes them ideal for recording the spontaneous firing pattern of $\mathrm{R} 15$ in the intact animal.

In six successful recordings from the hepatopancreas nerve branch, activity of the R15 axon could be identified easily in the reduced preparation, but in none of them could R15-like bursting activity be identified in the intact animals. For up to $4 \mathrm{~d}$ of recording (approximately $3 \mathrm{hr}$ of intermittent recordings per day) for one animal, R15 was either silent or beating at extremely low firing rates. Figure $14 A$ shows three random 1.5 min periods selected from a 2.5 -hr recording. Figure $14 B$ shows the activity of R15's soma spike in the reduced preparation and its bursting pattern recorded extracellularly from the fine nerve branch. No such bursting activity was recorded in the intact animal.

One possible explanation of why we recorded no R 15 bursting in the intact animals could be branch-specific block of the R 15 axon in the hepatopancreas nerve. To address this issue, we recorded from other $\mathrm{R} 15$ nerve branches in three additional experiments. In one animal the electrode was placed on the spermathecal nerve, which often contains an axon branch from R15 (Rittenhouse and Price, 1985). In two additional experi- ments, we recorded from the ventricular branch of the pericardial nerve (Mayeri et al., 1974). Although R15 bursting was clearly visible in all three animals in the reduced preparation examined at the end of the experiment, no R15 bursts were recorded in the intact animal. In all, $52 \mathrm{hr}$ of recording from nine animals failed to reveal any sign of R 15 bursting like that recorded in the isolated ganglion.

Several manipulations were used in an effort to trigger R15 bursting in the chronic preparations: exposure of the animal to low salinity (10\% hypotonic) ASW for $30 \mathrm{~min}$ and return to normal ASW, prolonged contact with another animal, feeding to satiation, warming of the ASW from $14^{\circ} \mathrm{C}$ to $18^{\circ} \mathrm{C}$, and recording from the animals at different times of the day/light cycle. None of these experimental conditions triggered R15 bursting activity. Although we cannot rule out the possibility that R15 bursting is suppressed by some unforeseen side effect of the surgery, our results are consistent with the hypothesis that R15 does not burst continuously in the intact animal. If it bursts at all, it apparently does so infrequently.

\section{Discussion}

$R 15 \alpha 1$ peptide may mediate R15's actions on the $R 25 / L 25$ network

Four types of evidence support the conclusion that R15 exerts its excitatory effect on the R25/L25 network by the release of 


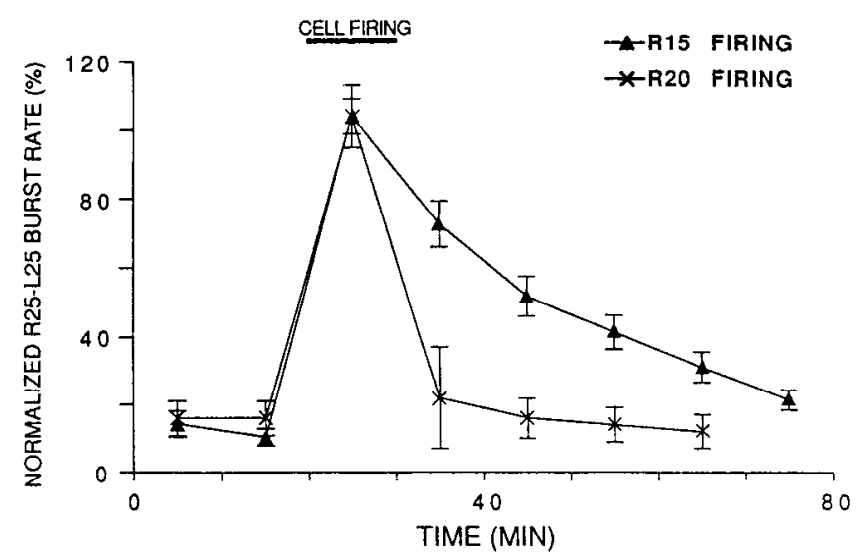

Figure 12. R15 produces a longer-lasting modulation of respiratory pumping than do the R20 cells. Firing R15 for $10 \mathrm{~min}$ at $3 \mathrm{~Hz}$ after 2 $\mathrm{hr}$ of hyperpolarization elicits an increase in the rate of respiratory pumping that decays over a 50-min period. In contrast, firing an R20 cell for the same amount of time at the same frequency elicits a change in respiratory pumping that decays shortly after $\mathrm{R} 20$ stops firing $(N=$ 4). The amplitudes of the two responses have been normalized so that their time courses of decay can be compared. Mean baseline and maximum values of respiratory pumping frequency for the $\mathrm{R} 15$ experiment were 0.7 and 5.8 per $10 \mathrm{~min}$; for the $\mathrm{R} 20$ experiment, the values were 1.6 and 10.4 per $10 \mathrm{~min}$. Error bars represent SEM.

R $15 \alpha 1$ peptide: (1) R 15 has been shown to synthesize the R $15 \alpha 1$ peptide (Weiss et al., 1989), and application of the peptide to the ganglion mimicks the effect on the network produced by firing R15, in sign (excitatory), in form (both weak and strong bursts are elicited), and in duration (both are long lasting). (2) Both R15 and exogenously applied R15 $\alpha 1$ peptide appear to act directly on the R25/L25 network, because both effects persist under conditions in which polysynaptic activity in the ganglion is greatly reduced. (3) The actions of R15 and the R15 1 peptide cross-desensitize. (4) Another of R15's three identified neuropeptides, R15 $\beta$ peptide, has no effect on the frequency of respiratory pumping. Taken together, these data are consistent with the hypothesis that the R $15 \alpha 1$ peptide mediates the excitatory modulatory action of R15 on the R25/L25 network.

\section{Modulation of the form of respiratory pumping by R15 and the R20 cells}

Different modulatory inputs or substances applied to the R25/ L25 circuit can produce different modes of behavioral output. The R20 cells and their putative transmitter, SCP, generate exclusively strong bursts in the R25/L25 network (Alevizos et al., 1989b). In contrast, R15 and the R15 $\alpha 1$ peptide elicit a mixture of strong and weak bursting. The production of different modes of behavior by the same neuronal circuit also has been reported for other central pattern generators. For example, the circuit that generates escape swimming in Tritonia can be modulated to generate withdrawal reflexes (Getting and Dekin, 1985; Getting, 1989), and the gastric mill oscillator of lobster can be switched between two different patterns of behavioral output by modulatory inputs (Selverston, 1989).

The different effects exerted by R15 and the R20 cells on respiratory pumping suggest that the two cell types may serve different physiological functions. R15 generates a long-lasting increase of both the strong and the weak R25/L25 bursting frequency, while the $\mathbf{R} 20$ cells produce a briefer increase, predominantly in the rate of strong bursts. Visual observations of

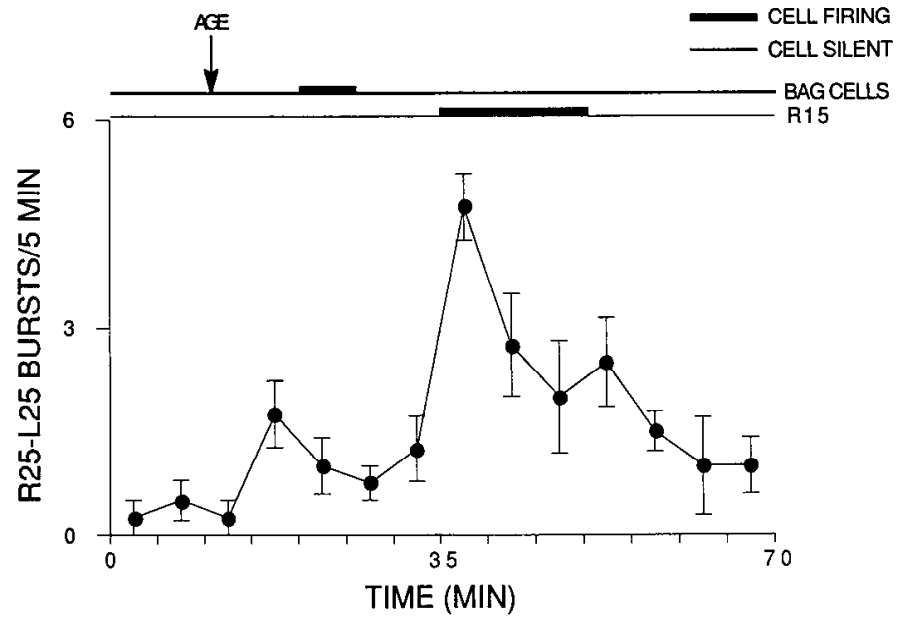

Figure 13. R15 activity is necessary and sufficient for modulation of respiratory pumping rate during bag cell discharge. The abdominal ganglion remained connected to the head ganglia via the pleuroabdominal connectives in this preparation. The head ganglia were kept isolated from the rest of the nervous system in a $1-\mathrm{ml}$ subchamber that was physically isolated from the main chamber. R15 was kept hyperpolarized from the start of the experiment while respiratory pumping rate was monitored in postsynaptic followers of the R25/L25 network. Bag cells were induced to discharge by application of AGE (1/8 of a homogenized atrial gland) on the head ganglia. Bag cell discharge began 9 \pm 2 min after AGE application. When R15 was released from hyperpolarization and allowed to burst spontaneously for $15 \mathrm{~min}$, beginning $15 \mathrm{~min}$ after the start of the bag cell discharge (which lasted $6 \pm 1 \mathrm{~min}$ ), there was an increase in the respiratory pumping rate. The change in the frequency of respiratory pumping elicited by R 15 bursting was not significantly different from the change recorded without previous firing of the bag cells $(N-4)$. The small increase in the rate of respiratory pumping immediately after AGE application was not studied further. Error bars represent SEM.

the contractions of the mantle organs and the heart during the weak bursting elicited by $R 15$ revealed no obvious qualitative difference from the contractions during the strong bursts. Rather, the difference seems to be mostly quantitative; that is, heart inhibition and siphon and gill contractions were weaker during weak bursting than during strong bursting. Further work will be required to determine the functional significance of the two different types of respiratory pumping.

The R 15 and the $R 20$ cells also differ in their ability to elicit repeated responses in the $\mathrm{R} 25 / \mathrm{L} 25$ network. The synaptic action of R15 exhibits pronounced desensitization that may limit the time course of R15's effect on the frequency of respiratory pumping. In contrast, the effects produced by the R20 cells do not desensitize appreciably (Alevizos, 1989).

\section{Physiological roles of $R 15$ and the R20 cells in modulating the} frequency of respiratory pumping

The long-lasting nature of the modulatory effects of R15 and the $R 20$ s cells, as well as the different patterns of modulation they produce, suggests that variable patterns of activity in these modulatory inputs to the R25/L25 cells may contribute to the variability observed across and within animals in the rate of respiratory pumping (Eberly et al., 1981). In addition, the identification of these two sources of modulatory input should prove useful in determining the mechanisms by which environmental and physiological stimuli modulate respiratory pumping behavior. The physiological conditions under which the R20 cells 


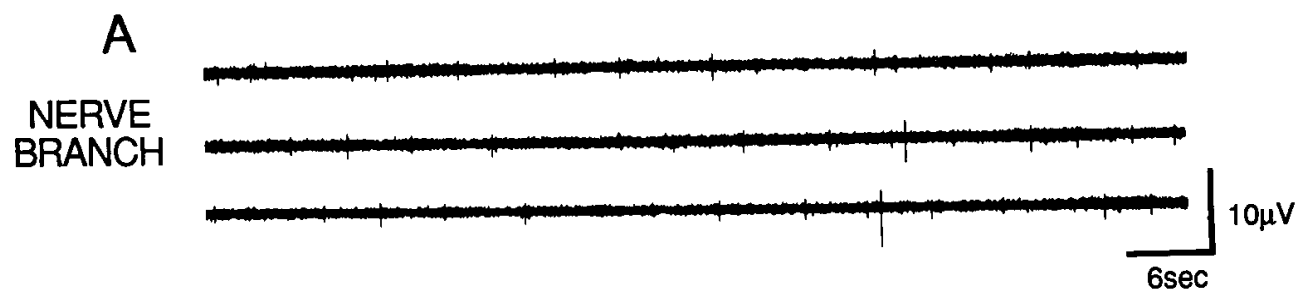

B

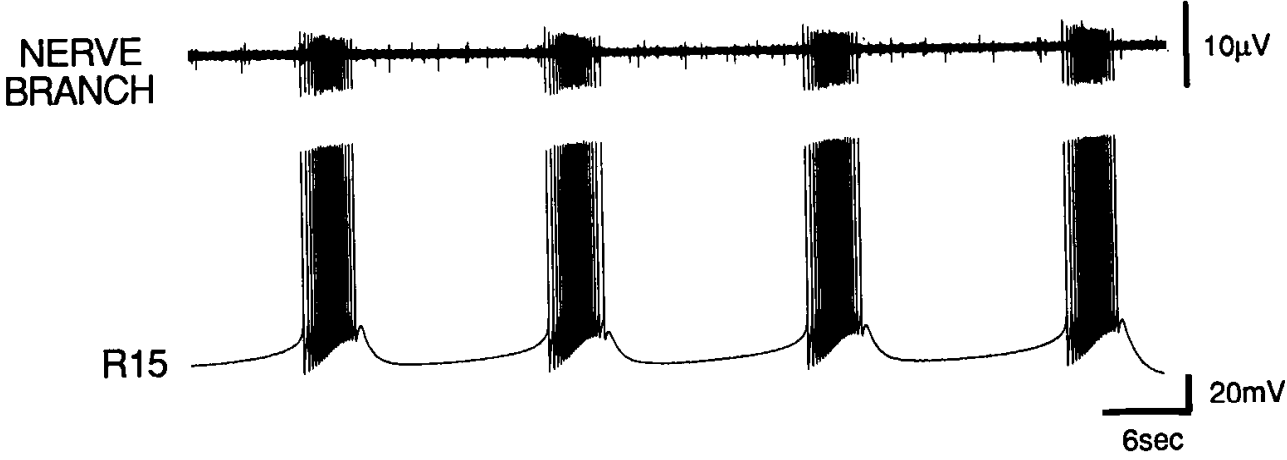

Figure 14. R15 does not burst spontaneously in the intact animal. An extracellular electrode chronically implanted into the subject was used to record activity from a small branch of the pericardial nerve that runs from the major nerve trunk to the mesentery of the hepatopancreas, which is innervated by R15's processes. $A$, In the intact animal there was no activity in R15 under a variety of experimental conditions. Three random $1.5-\mathrm{min}$ samples are shown from a 2 -hr recording in the intact animal. $B$. At the end of the experiment, the animal was killed, and the abdominal ganglion was dissected from the animal, along with the electrode still attached to the nerve branch. Bursting activity was recorded in the nerve of the isolated ganglion. Intracellular recording from the R 15 soma showed that the bursting activity in the nerve was due to R15. These data are representative of $52 \mathrm{hr}$ of recording from nine animals. are activated are not yet known, though indirect evidence (Alevizos, 1989) suggests that they may be responsible for the spontaneous seizures of respiratory pumping observed in the intact animal (Kanz and Quast, 1990). R15, on the other hand, is likely to be activated during egg laying (Branton et al., 1978). Although there is no direct evidence that respiratory pumping increases during spontaneous egg-laying behavior, it has been reported to increase following bag-cell bursts triggered in vitro (Schaefer and Brownell, 1986). Our results, together with the data showing that the bag cells excite R 15 (Branton et al., 1978), suggest that, if the bag cells increase the rate of respiratory pumping in vivo, they may do so in part by exciting R 15 .

\section{$R 15$ bursting is suppressed in the intact animal}

We could find no evidence that R 15 bursts continuously in the intact animal. Although we cannot rule out nonburst firing of $\mathrm{R} 15$, its frequency must be quite low, as illustrated by Figure $14 \mathrm{~A}$. Our working hypothesis is that, in vivo, $\mathrm{R} 15$ is a conditional burster, and that its burst activity is normally suppressed. It seems likely that $\mathrm{R} 15$ burst generation is triggered in vivo when a bag-cell burst initiates egg laying. However, because no spontaneous bouts of egg laying occurred during our chronic recording experiments, this question remains open.

The lack of R15 bursting in the intact animal has two important consequences for its physiological actions. First, were R15 to burst continuously, its synaptic outputs would be permanently blocked by desensitization. The lack of continuous bursting in the intact animal means that, when R15 does burst, the synaptic actions described here and in the two companion papers can be expressed. Second, Kramer and Levitan (1990) have shown that there is an activity-dependent suppression of R15's responses to two excitatory modulators, egg-laying hormone (ELH) and 5-HT. If R15 is silent when ELH or 5-HT is applied, the modulation of the currents that generate the bursting is maximal, while when R15 is bursting the effects of these modulators are minimal. To exhibit a maximum response to
ELH during the bag cell discharge, R15 must be silent when ELH is released.

\section{References}

Adams WB, Benson JA (1985) The generation and modulation of endogenous rhythmicity in the Aplysia bursting pacemaker neurone R15. Prog Biophys Mol Biol 46:1-49.

Alevizos A (1989) Central and peripheral effects of the neurosecretory cell R15 of Aplysia. PhD dissertation, Columbia University.

Alevizos A, Weiss KR, Koester J (1989a) R15 activates respiratory pumping, motoneuron L7, and the hermaphroditic duct in Aplysia. Soc Neurosci Abstr 15:1140.

Alevizos A, Weiss KR, Koester J (1989b) The SCP containing R20 neurons modulate respiratory pumping in Aplysia. J Neurosci 9:30583071.

Alevizos A, Weiss KR, Koester J (1991a) Synaptic actions of identified peptidergic neuron R15 in Aplysia. II. Contraction of pleuroabdominal connectives mediated by motoneuron L7. J Neurosci 11:12751281.

Alevizos A, Weiss KR, Koester J (1991b) Synaptic actions of identified peptidergic neuron R15 in Aplysia. III. Activation of the large hermaphroditic duct. J Neurosci 1 1:1282-1290.

Arvanitaki A, Chalazonitis N (1958) Configurations modales de l' activitê propre à diffèrent neurones d' un même centre. J Physiol (Paris) 50:122-125.

Bablanian GM, Treistman SN (1983) Seawater osmolarity influences bursting pacemaker activity in intact Aplysia californica. Brain Res 271:342-345.

Bablanian G, Treistman S (1985) The effect of hyperpolarization of cell R15 on the hemolymph composition of intact Aplysia. J Comp Physiol 155:297-303.

Beiswanger CM, Jacklet JW (1975) In vitro tests for a circadian rhythm in the electrical activity of a single neuron in Aplysia californica. $\mathrm{J}$ Comp Physiol 103:19-37.

Benson JA, Adams WB (1989) Ionic mechanisms of endogenous activity in molluscan burster neurons. In: Neuronal and cellular oscillators (Jacklet JW, ed), pp 87-120. New York: Dekker.

Berry RW (1976) Processing of low molecular weight proteins by identified neurons of Aplysia. J Neurochem 26:229-231.

Branton DW, Mayeri E, Brownell P, Simon SS (1978) Evidence for local hormonal communication between neurones in Aplysia. Nature 274:70-72. 
Buck LB, Bigelow JM, Axel R (1987) Alternative splicing in individual Aplysia neurons generates neuropeptide diversity. Cell 51:127-133.

Byrne J (1983) Identification and initial characterization of a cluster of command and pattern-generating neurons underlying respiratory pumping in Aplysia californica. J Neurophysiol 49:491-508.

Byrne J, Koester J (1978) Respiratory pumping: neuronal control of a centrally commanded behavior in Aplysia. Brain Res 143:87-105.

Coggeshall RE (1967) A light and electron microscope study of the abdominal ganglion of Aplysia californica. J Neurophysiol 30:12631287.

Eberly L, Kanz J, Taylor C, Pinsker H (1981) Environmental modulation of a central pattern generator in freely behaving Aplysia. Behav Neural Biol 32:21-34.

Frazier WT, Kandel ER, Kupfermann I, Waziri R, Coggeshall RE (1967) Morphological and functional properties of identified neurons in the abdominal ganglion of Aplysia californica. J Neurophysiol 30: 1288-1351.

Gainer H, Loh YP, Sarne Y (1977) Biosynthesis of neuronal peptides. In: Peptides in neurobiology (Gainer H, ed), pp 183-219. New York: Plenum.

Getting PA (1989) A network oscillator underlying swimming in Tritonia. In: Neuronal and cellular oscillators (Jacklet JW, ed), pp $215-$ 236. New York: Dekker.

Getting PA, Dekin MS (1985) Mechanisms of pattern generation underlying swimming in Tritonia. IV. Gating of central pattern generator. J Neurophysiol 53:466-480.

Hening WA (1982) Central generation and coordination of a complex behavioral sequence in Aplysia californica: locomotion and respiratory pumping. PhD thesis, New York University.

Kanz JE, Quast WD (1990) Respiratory pumping seizure: a newly discovered spontaneous stereotyped behavior pattern in the opisthobranch mollusc Aplysia californica. J Comp Physiol A 166:619-627.

Koch UT, Brunner M (1985) The velocity filter, a system for recording on line decomposition of complex extracellular spike trains by analog computing. J Comp Physiol A 157:823-830.

Koester J (1989) Chemically and electrically coupled interneurons mediate respiratory pumping in Aplysia. J Neurophysiol 62:11131126.

Koester J, Kandel ER (1977) Further identification of neurons in the abdominal ganglion of Aplysia using behavioral criteria. Brain Res 121:1-20.

Kramer RH, Levitan IB (1990) Activity-dependent neuromodulation in Aplysia neuron R 15 : intracellular calcium antagonizes neurotransmitter responses mediated by cAMP. J Neurophysiol 63:1075-1088.

Kupfermann I, Weiss KR (1976) Water regulation by a presumptive hormone contained in identified neurosecretory cell R15 of Aplysia. J Gen Physiol 67:113-123.

Lickey ME, Block GD, Hudson DJ, Smith JT (1976) Circadian oscillators and photoreceptors in the gastropod, Aplysia. Photochem Photobiol 23:361-366.

I loyd PE, Mahon AC, Kupfermann I, Cohen JL, Scheller RH, Weiss
KR (1985) Biochemical and immunocytological localization of molluscan small cardioactive peptides in the nervous system of Aplysia californica. J Neurosci 5:1851-1861.

Lloyd PE, Kupfermann I, Weiss KR (1987) Sequence of small cardioactive peptide $A$ : a second member of a class of neuropeptides in Aplysia. Peptides 8:179-184.

Mayeri E, Koester J, Kupfermann I, Liebeswar G, Kandel ER (1974) Neural control of circulation in Aplysia. I. Motoneurons. J Neurophysiol 37:458-475.

Morris HR, Panico M, Karplus A, Lloyd PE, Riniker B (1982) Elucidation by FAB-MS of the structure of a new cardioactive peptide from Aplysia. Nature 300:643-645.

Painter SD, Rock MK, Nagle GT, Blankenship JE (1988) Peptide B induction of bag-cell activity in Aplysia: localization of sites of action to the cerebral and pleural ganglia. J Neurobiol 19:695-706.

Parsons DW, Ter Maat A, Pinsker HM (1983) Selective recording and stimulation of individual identified neurons in freely behaving $A p l y$ sia. Science 221:1203-1206.

Rittenhouse AR, Price CH (1985) Peripheral axons of the parabolic burster neuron R15. Brain Res 333:330-335.

Sawada M, Blankenship JE, McAdoo DJ (1981) Neural control of a molluscan blood vessel, anterior aorta of Aplysia. J Neurophysiol 46: 967-986.

Schaefer M, Brownell PH (1986) Modulation of a respiratory motor program by peptide-secreting neurons in Aplysia. J Neurobiol 17: $121-126$.

Schlapfer WT, Woodson PBJ, Tremblay JP, Barondes SH (1974) Depression and frequency facilitation at a synapse in Aplysia californica: evidence for regulation by availability of transmitter. Brain Res 76 : 267-280.

Selverston AI (1989) Lobster gastric mill oscillator. In: Neuronal and cellular oscillators (Jacklet JW, ed), pp 339-370. New York: Dekker.

Skinner TL, Peretz B (1989) Age sensitivity of osmoregulation and of its neural correlates in Aplysia. Am J Physiol 256:R989-R996.

Stinnakre J, Tauc L (1969) Central neuronal response to the activation of osmoreceptors in the osphradium of Aplysia. J Exp Biol 51:347361 .

Strumwasser F (1965) The demonstration and manipulation of a circadian rhythm in a single neuron. In: Circadian clocks (Aschoff $\mathrm{J}$, ed), pp 442-462. Amsterdam: North Holland.

ter Maat A, Koppe JA, Pinsker HM (1983) Analysis of hormones and behavior in intact Aplysia. In: Molluscan neuroendocrinology (Lever J, Boer HH, eds), pp 243-250. New York: North Holland.

Weiss KR, Bayley H, Lloyd PE, Tenenbaum R, Gawinowicz Kolks MA, Buck L, Cropper EC, Rosen SC, Kupfermann I (1989) Purification and sequencing of neuropeptides contained in neuron R15 of Aplysia californica. Proc Natl Acad Sci USA 86:2913-2917.

Woodson PBJ, Schlapfer WT (1979) The amplitude of post-tetanic potentiation of the EPSP RC1-R15 in Aplysia is modulated by environmental parameters. Brain Res 173:225-242. 